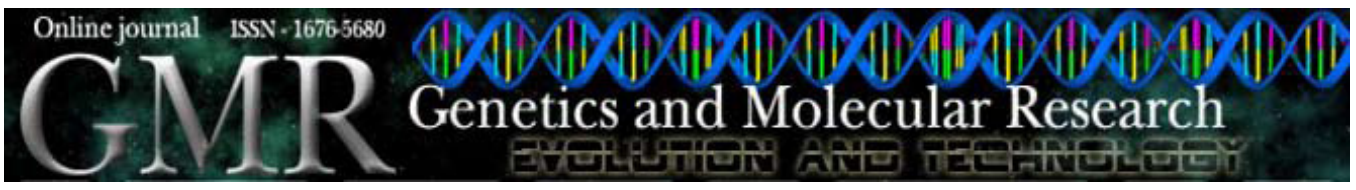

\title{
Joint analysis of beef growth and carcass quality traits through calculation of co-variance components and correlations
}

\author{
H.R. Mirzaei ${ }^{1}$, A.P. Verbyla ${ }^{2}$ and W.S. Pitchford ${ }^{3}$ \\ ${ }^{1}$ Department of Animal Science, Zabol University, Mofatteh St., Zabol, Iran \\ ${ }^{2}$ BiometricsSA, The University of Adelaide, Waite Campus, Glen Osmond SA, \\ Australia \\ ${ }^{3}$ Animal Science, University of Adelaide, Roseworthy SA, Australia \\ Corresponding author: H.R. Mirzaei \\ E-mail: president@imamreza.ac.ir / h.mirzaei9@gmail.com
}

Genet. Mol. Res. 10 (1): 433-447 (2011)

Received October 15, 2010

Accepted January 26, 2011

Published March 15, 2011

DOI 10.4238/vol10-1gmr1108

\begin{abstract}
A joint growth-carcass model using random regression was used to estimate the (co)variance components of beef cattle body weights and carcass quality traits and correlations between them. During a four-year period (1994-1997) of the Australian "southern crossbreeding project", mature Hereford cows $(\mathrm{N}=581)$ were mated to 97 sires of Jersey, Wagyu, Angus, Hereford, South Devon, Limousin, and Belgian Blue breeds, resulting in 1141 calves. Data included 13 (for steers) and 8 (for heifers) body weight measurements approximately every 50 days from birth until slaughter and four carcass quality traits: hot standard carcass weight, rump fat depth, rib eye muscle area, and intramuscular fat content. The mixed model included fixed effects of sex, sire breed, age (linear, quadratic and cubic), and their interactions between sex and sire breed with age. Random effects were sire, dam, management (birth location, year, post-weaning groups), and permanent environmental effects, and their interactions with linear, quadratic and cubic growth, when possible. Phenotypic, sire and dam correlations between body weights and hot standard carcass weight and rib eye muscle area were
\end{abstract}


positive and moderate to high from birth to feedlot period. Management variation accounted for the largest proportion of total variation in both growth and carcass traits. Management correlations between carcass traits were high, except between rump fat depth and intramuscular fat $(\mathrm{r}=$ 0.26). Management correlations between body weight and carcass traits during the pre-weaning period were positive except for intramuscular fat. The correlations were low from birth to weaning, then increased dramatically and were high during the feedlot period.

Key words: Crossbred cattle; Growth; Carcass traits; Correlations; Random regression

\section{INTRODUCTION}

The optimization of cattle production systems including the evaluation of alternative management and marketing strategies requires knowledge of the variation in body weights and carcass traits and the association between them. Successful prediction of economically important carcass quality traits of cattle following a specific growth path depends as much on a correct estimation of (co)variance components of its genotype parameters as on a detailed description of its environment (Crews Jr. et al., 2003; Baker et al., 2006). It is then possible to estimate the correlations between growth and carcass quality traits over the entire growth period and finally predict carcass quality traits from live growth traits (Kahi et al., 2007; Lambe et al., 2007). Kilpatrick and Steen (1999) reported that the estimates of (co)variance components will lead to the establishment of carcass correlation curves over time and the development of a predictive model. In many published articles, covariances between growth and carcass traits at specific (discrete) ages are provided (Bergen et al., 2006a,b; Smith et al., 2007), and essential information regarding the estimation of covariances between longitudinal growth data and carcass quality traits is often lacking.

Therefore, the main objective of this study was to estimate genetic and non-genetic covariances between longitudinal body weights and carcass quality traits using the joint growth-carcass sire model with random regression. Hence, a major point of interest in this study was to answer a basic question: how does the correlation between live weight and carcass traits change over time?

\section{MATERIAL AND METHODS}

\section{Animals and management}

Animals from the "Southern Crossbreeding Project" were used for this study. The Project was designed to determine variations between and within breeds with the aim of improving the utilization of existing breeds for meeting a range of market specifications in southern Australia (Pitchford et al., 2002). Purebred Hereford cows (581) were mated to semen of 7 sire breeds: Angus (11 sires), Belgian Blue (16 sires), Hereford (10 sires), Jersey (12 sires), Limousin (16 sires), South Devon (15 sires), and Wagyu (17 sires). Of the 637 cows that calved, 581 had progeny that survived to slaughter and were used in the analysis herein. There 
were generally $12-15$ progeny per sire, with an average of 13 calves per sire and 14 sires per breed. Sires were generally used in one year only, whereas dams were commonly used for more than one year. All cows were 3 years or older when calving, so no maiden heifers were used. They were artificially inseminated in June and July the previous year, and if they did not conceive with two insemination attempts, they were removed from the experiment until the next mating. The project comprised 1141 of the heifers (female) and steers (castrated male) born in autumn (average birth date April 3rd) at two locations; "Struan" near Naracoorte and "Wandilo" near Mount Gambier in the southeast part of South Australia. Calves were weaned in summer (mid-December-early January) at 250 to 300 days of age. At weaning, all calves born at Wandilo were transferred to Struan. Calves stayed with their dams on pasture until weaning, were grown until 12 to 18 months of age, and then transported to a commercial feedlot (Pitchford et al., 2002). All cattle were slaughtered commercially at abattoirs, and they were processed depending on which market they were to be sent.

\section{Live body weights}

Live body weights (unfasted) consisted of 13 measurements for steers and 8 measurements for heifers at approximately every 50 days from birth until slaughter. Table 1 shows summary statistics of the weight-age array from birth to slaughter for steers and heifers. The means were averaged over all four years. The standard deviation for live weight of both heifers and steers increased from the first to the last weighing (Table 1). To overcome this heterogeneous variance, the use of the natural logs of the body weights rather than the original body weights seemed sensible. Thus,

$$
\begin{aligned}
& y_{t}=\ln (B W)_{t} \sim N\left(\mu_{t}, \sigma^{2}{ }_{t}\right) \\
& B W=\exp \left(y_{t}\right)
\end{aligned}
$$

\begin{tabular}{|c|c|c|c|c|c|c|c|}
\hline \multicolumn{4}{|c|}{ Heifers } & \multicolumn{4}{|c|}{ Steers } \\
\hline Mean (day) & SD & Mean $(\mathrm{kg})$ & SD & Mean (day) & SD & Mean (kg) & $\mathrm{SD}$ \\
\hline 0 & 0 & 36.54 & 6 & 0 & 0 & 39.01 & 6 \\
\hline 75 & 22 & 93.32 & 23 & 75 & 22 & 98.10 & 24 \\
\hline 125 & 21 & 124.22 & 29 & 125 & 22 & 130.93 & 30 \\
\hline 175 & 19 & 17.52 & 36 & 175 & 20 & 183.02 & 38 \\
\hline 230 & 26 & 239.84 & 43 & 230 & 27 & 256.00 & 44 \\
\hline 280 & 28 & 277.66 & 40 & 280 & 29 & 295.61 & 40 \\
\hline 330 & 32 & 296.44 & 50 & 330 & 33 & 303.38 & 42 \\
\hline 415 & 20 & 333.50 & 48 & 387 & 32 & 329.40 & 37 \\
\hline- & - & - & - & 438 & 36 & 349.23 & 40 \\
\hline- & - & - & - & 482 & 27 & 353.09 & 48 \\
\hline- & - & - & - & 545 & 36 & 414.13 & 70 \\
\hline- & - & - & - & 593 & 44 & 481.82 & 92 \\
\hline- & - & - & - & 630 & 65 & 532.61 & 110 \\
\hline
\end{tabular}

where $\mathrm{y}_{\mathrm{t}}$ is normally distributed with mean $\mu_{\mathrm{t}}$ and variance $\sigma_{\mathrm{t}}^{2}$ that depend on $t$.

Number of observations $=1141$.

The mean and variance of body weight are therefore given by $\exp \left(\mu+\sigma^{2} / 2\right)$ and $\exp$ $\left[2\left(\mu+\sigma^{2}\right)\right]-\exp \left(2 \mu+\sigma^{2}\right)$, respectively. 
Growth (natural log of body weight) had an approximately cubic pattern, and the cubic polynomial in the time formed the basis of the model considered in the current study. Age was centered (mean subtracted) and scaled (from days to years). This was done for both numerical reasons and for prediction. In the former case, changes in one predictor could be gauged by setting others at their mean, i.e., at the new origin for centered age, and in the latter, (co)variance components were more easily estimated because they were larger.

\section{Carcass quality traits}

The four primary traits affecting carcass value in Australia are hot standard carcass weight (HSCW), P8 fat depth (P8), rib eye muscle area (EMA), and intramuscular fat content (IMF). HSCW and P8 fat depth were assessed based on a standard trim and locations (AUSMEAT, 1995). EMA was measured at the site of quartering. Commercial constraints produced variation in the site of quartering, so the EMA was adjusted as described by Pitchford et al. (2006). IMF was the chemical extraction of fat from a meat sample taken as a slice (approximately $100 \mathrm{~g}$ ) off the longissimus dorsi, generally between the 12th and 13th ribs (Pitchford et al., 2002). Table 1 lists the means and standard deviations of the carcass quality traits considered in this study for heifers and steers. Most carcass traits exhibited a skewed distribution (data not shown) and so were transformed. The separation with respect to slaughter age reflects the different management systems for heifers and steers.

\section{Statistical analysis}

A joint growth-carcass sire mixed model was fitted using ASREML (Gilmour et al., 2000) to estimate the covariance components and correlations among genetic and environmental components of the body weights and carcass quality traits. The mixed model fitted was of the form

$$
\mathbf{y}=X \boldsymbol{\tau}+Z \mathbf{u}+\mathbf{e}
$$

where $X$ is the incidence matrix of fixed effects; $\tau$ is the vector of fixed effects; $Z$ is the incidence matrix for random effects; $u$ is the vector of random effects; $e$ is the vector of random errors (temporary environmental effect or measurement error), NID $\left(0, \sigma^{2}\right)$.

The vector $y$ contains both the growth and carcass measurements. The fixed effects are as for the individual analysis of growth and carcass traits. Thus,

$$
\mathbf{X}=\begin{array}{cc}
\mathbf{X}_{1} & \mathbf{0} \\
\mathbf{0} & \mathbf{X}_{2}
\end{array}
$$

where $X_{1}$ is the design matrix for the growth fixed effects and $X_{2}$ is the design matrix for the carcass fixed effects. The fixed effects fitted are listed below and the final random effects fitted are reported in Table 2 . Symbolically,

Growth $\sim$ Sex, Sire Breed, Age, Age ${ }^{2}$, Age $^{3}$

Sex.Age, Sex.Age ${ }^{2}$, Sex.Age ${ }^{3}$

Breed.Age, Breed.Age ${ }^{2}$, Breed.Age ${ }^{3}$

Carcass $\sim$ Sex, Sire Breed, Slaughter age within sex. 
In the model for the $\mathrm{i}^{\text {th }}$ animal there is $\mathbf{u}_{\mathrm{i}} \sim \mathrm{N}(\mathbf{0}, \mathbf{G})$, where $u_{i}$ is the $16 \mathrm{x} 1$ vector of random effects, which consist of mean, linear, quadratic, and cubic terms for each of the four component random effects (Sire (S), Dam (D), Management (M), and Permanent environmental (P)). Initially, an animal model was fitted, but many more components could be estimated using the sire model. An unfortunate outcome of this is that the maternal effect includes some additive genetic variance in addition to just maternal (milk yield, etc.).

The matrix $\mathbf{G}$ is $32 \times 32$ and has the form

$$
\mathrm{G}=\left(\left[\begin{array}{cccc}
\mathrm{G}_{\mathrm{S}} & 0 & 0 & 0 \\
0 & \mathrm{G}_{\mathrm{D}} & 0 & 0 \\
0 & 0 & \mathrm{G}_{\mathrm{M}} & 0 \\
0 & 0 & 0 & \mathrm{G}_{\mathrm{P}}
\end{array}\right]\right)
$$

and each $G_{j}(j=S, D, M$, or $P)$ is $8 \times 8$ as reported in Table 2 .

An important point is that the permanent environmental effects for carcass traits correspond to the residual term for these traits and are hence total (include temporary) environmental variances. The overall residual modeled as $\sigma 2 \mathrm{I}$ (temporary environmental that is constant variance and uncorrelated) was estimated from the live weight data only.

\section{Calculation of correlations}

The main objective of this study was to estimate corresponding correlations between growth path (longitudinal body weights) and carcass quality traits (Equation 1), namely

$$
\rho\left(\operatorname{lnc}_{\mathrm{ij}}, \operatorname{lng}_{\mathrm{ijt}}\right)=\frac{\operatorname{cov}\left(\operatorname{lnc}_{\mathrm{ij}}, \operatorname{lng}_{\mathrm{ijt}}\right)}{\sqrt{\left(\operatorname{var} \operatorname{lnc}_{\mathrm{ij}}\right) \operatorname{var}\left(\operatorname{lng}_{\mathrm{ijt}}\right)}}
$$

where $\ln c_{i j}$ is $\log$ of $\mathrm{i}^{\text {th }}$ carcass trait of $\mathrm{j}^{\text {th }}$ calf; $\ln g_{i j t}$ is $\log$ of $\mathrm{i}^{\text {th }}$ body weight of $\mathrm{j}^{\text {th }}$ calf at time $\mathrm{t}$; $\operatorname{var}\left(\ln g_{i j t}\right)$ is the variance of growth components; $\operatorname{var}\left(\ln c_{i j}\right)$ is the variance of transformed growth components, and $\operatorname{cov}\left(\ln c_{i j}, \ln g_{i j}\right)$ is the covariance between transformed growth and carcass traits. Using properties of the log-normal distribution (Aitchison and Brown, 1963; Limpert et al., 2001), it follows that the correlation between $\mathrm{c}_{\mathrm{ij}}$ and $\mathrm{g}_{\mathrm{ijt}}$ is given by

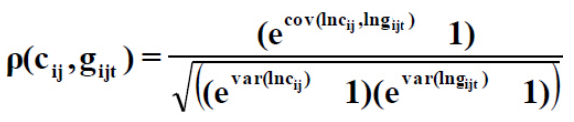

Thus, the variance of growth components $\left(\operatorname{var}\left(\ln g_{i j t}\right)\right)$, the variance of carcass quality traits $\left(\operatorname{var}\left(\ln c_{i j}\right)\right)$, and the covariance between growth and carcass quality traits $\left(\operatorname{cov}\left(\ln c_{i j}, \ln g_{i j t}\right)\right)$ need to be determined from the joint model.

First, the variance of each component can be shown to be

$$
\begin{aligned}
& \operatorname{var}\left(\operatorname{lng}_{\mathrm{ijt}}\right)=\mathrm{V}_{\mathrm{CON}}^{2}+\mathrm{t}^{2} \cdot \mathrm{V}^{2} \mathrm{Age}_{\mathrm{H}}+\mathrm{t}^{4} \cdot \mathrm{V}^{2}{ }_{\mathrm{Age}}{ }^{2}+\mathrm{t}^{6} \mathrm{~V}^{2} \mathrm{Age}^{3} \\
& +2 \cdot \mathrm{t} \cdot \mathrm{COV}_{\mathrm{CON}, \mathrm{Age}}+2 \cdot \mathrm{t}^{2} \cdot \mathrm{COV}_{\mathrm{CON}, \mathrm{Age}}+2 \cdot \mathrm{t}^{3} \cdot \mathrm{COV}_{\mathrm{CON}, \mathrm{Age}} \\
& +2 \cdot \mathrm{t}^{3} \cdot \mathrm{COV}_{{\mathrm{Age}, A g \mathrm{Ag}^{2}}^{2}}+2 \cdot \mathrm{t}^{4} \cdot \mathrm{COV}_{\mathrm{Age}, \mathrm{Age}^{3}}+2 \cdot \mathrm{t}^{5} \cdot \mathrm{COV}_{\mathrm{Age}^{2}, \mathrm{Age}^{3}}
\end{aligned}
$$


The variance of carcass $\left(\operatorname{var}\left(\ln c_{i j}\right)\right)$ is independent of time and estimated by the joint model. The covariance between body weights and each carcass trait, that is, $\operatorname{cov}\left(\operatorname{lnc}_{\mathrm{ij}} \operatorname{lng}_{\mathrm{ijt}}\right)$, is given by

$\operatorname{cov}\left(\operatorname{lnc}_{\mathrm{ij}}, \operatorname{lng} \mathrm{ij}_{\mathrm{ij}}\right)=\mathrm{COV}_{\mathrm{CON}, \mathrm{CARCASS}}+\mathrm{t} \cdot \mathrm{COV}_{\mathrm{Age,CARCASS}}+2 \cdot \mathrm{t}^{2} \cdot \mathrm{COV}_{\mathrm{Age}^{2}, \mathrm{CARCASS}}+\mathrm{t}^{3} \cdot \mathrm{COV}_{\mathrm{Age}^{3}, \text { CARCASS }} \quad$ (Equation 4)

As a result of fitting such a highly parameterized model, at some ages these covariances may be slightly outside the allowable range, resulting in correlation estimates greater than 1 .

\section{RESULTS AND DISCUSSION}

\section{Growth (co)variance components}

Estimates of sire (additive genetic), dam (additive + maternal), management group, and permanent environmental variance components for the growth and carcass quality traits and correlations between them are given in Table 2. Cubic random coefficient models were postulated

Table 2. Variances and correlations ${ }^{\mathrm{a}}$ of random effects ${ }^{\mathrm{b}}$ (sire and dam) of growth ${ }^{\mathrm{c}}$, and carcass quality traits ${ }^{\mathrm{d}}$.

\begin{tabular}{|c|c|c|c|c|c|c|c|c|}
\hline Sire & Mean & Age & $\mathrm{Age}^{2}$ & $\mathrm{Age}^{3}$ & HSCW & P8 & EMA & IMF \\
\hline Mean & 4.94 & & & & & & & \\
\hline Age & 0.80 & 0.50 & & & & & & \\
\hline $\mathrm{Age}^{2}$ & 0 & 0 & 1.41 & & & & & \\
\hline $\mathrm{Age}^{3}$ & 0 & 0 & 0 & 0 & & & & \\
\hline $\mathrm{HSCW}$ & 0.99 & 0.90 & 0 & 0 & 10.70 & & & \\
\hline P8 & 0.03 & 0.41 & 0 & 0 & 0.08 & 106.85 & & \\
\hline EMA & 0.90 & 0.03 & 0 & 0 & 0.99 & -0.22 & 8.34 & \\
\hline IMF & -0.12 & 0.90 & 0 & 0 & 0.14 & 0.29 & -0.14 & 49.95 \\
\hline \multicolumn{9}{|l|}{ Dam } \\
\hline Mean & 54.90 & & & & & & & \\
\hline Age & -0.76 & 20.20 & & & & & & \\
\hline $\mathrm{Age}^{2}$ & 0 & 0 & 1.00 & & & & & \\
\hline $\mathrm{Age}^{3}$ & 0 & 0 & 0 & 0 & & & & \\
\hline HSCW & 1.00 & -0.15 & 0 & 0 & 35.50 & & & \\
\hline P8 & 0.48 & -0.02 & 0 & 0 & 1.00 & 115.00 & & \\
\hline EMA & 0.51 & -0.11 & 0 & 0 & 1.00 & 0.40 & 34.70 & \\
\hline IMF & 0.26 & -0.08 & 0 & 0 & 0.58 & -0.01 & 0.05 & 50.90 \\
\hline \multicolumn{9}{|c|}{ Management group } \\
\hline Mean & 56.10 & & & & & & & \\
\hline Age & -0.74 & 139.00 & & & & & & \\
\hline $\mathrm{Age}^{2}$ & -0.48 & 0.43 & 171.00 & & & & & \\
\hline $\mathrm{Age}^{3}$ & 0.40 & -0.69 & 0.18 & 373.00 & & & & \\
\hline HSCW & 0 & 0 & 0.73 & 0.49 & 42.50 & & & \\
\hline P8 & 0 & -0.23 & 0.71 & 0.64 & 0.82 & 632.00 & & \\
\hline EMA & 0 & 0 & 0.70 & 0.29 & 0.90 & 0.83 & 58.10 & \\
\hline IMF & 0 & 0.32 & 0.51 & 0.09 & 0.76 & 0.26 & 0.56 & 797.00 \\
\hline \multicolumn{9}{|c|}{ Permanent environmental (residual for carcass traits) } \\
\hline$\overline{\text { Mean }}$ & 30.70 & & & & & & & \\
\hline Age & -0.38 & 21.40 & & & & & & \\
\hline $\mathrm{Age}^{2}$ & -0.35 & 0.58 & 23.00 & & & & & \\
\hline $\mathrm{Age}^{3}$ & 0 & 0 & 0 & 0 & & & & \\
\hline $\mathrm{HSCW}$ & 0 & 0 & 0 & 0 & 0 & & & \\
\hline P8 & 0.16 & 0.22 & -0.19 & 0 & 0 & 1066.91 & & \\
\hline EMA & 0.30 & 0.07 & -0.14 & 0 & 0 & 0.00 & 41.40 & \\
\hline IMF & -0.03 & 0.07 & 0.12 & 0 & 0 & 0.12 & -0.02 & 906.00 \\
\hline
\end{tabular}

${ }^{\mathrm{a}}$ Correlations below diagonal. ${ }^{\mathrm{b}}$ Variances have been multiplied by $10^{4}$ to ease reporting ${ }^{\mathrm{c}}$ mean, linear, quadratic, and cubic degree of age. ${ }^{\mathrm{d}} \mathrm{HSCW}=$ hot standard carcass weight; $\mathrm{P} 8=$ rump fat depth; EMA = rib eye muscle area; $\mathrm{IMF}=$ intramuscular fat content. Note that all variables were $\log$ transformed and age was in years (not days). Zero means that traits were not measurable. 
for each of the four sources of variation (sire, dam, permanent environmental, and management effects). In many cases, the data did not support inclusion of all terms because there was a failure in convergence when fitting the model. Estimated components that are listed as zero were on the boundary; that is, they converged to zero. The quadratic variances were very small for sire and dam, and we were not able to estimate their covariances (Table 2). In total, 24 (of 40) (co)variance components could be estimated for the growth traits (Table 2). None of the correlations between growth parameters (mean, linear, etc.) were extraordinarily high (maximum 0.80 ).

Estimates of total variance for each random component, i.e., sire, dam, permanent environmental, and environmental effects, variances, were plotted against time (Figure 1). The sire variance was lowest but increased with time as expected in agreement with Rekaya et al. (1999) and Schenkel et al. (2004). The dam variances were low and tended to be constant throughout the trajectory (Figure 1). It decreased from birth but was always higher than the sire variance. The trend in dam variances was consistent with Fischer et al. (2004) who reported constant dam variances over growth path (500 days) for sheep. Based on size scaling, 500 days in sheep is likely equivalent to approximately 1000 days in cattle, thus covering the range analyzed herein. Other studies with cattle have shown that maternal variance declines with age (Meyer, 2002). Perhaps, the discrepancy found in various studies may be attributed to partitioning problems between maternal genetic and permanent environmental effects. The permanent environmental variance was slightly lower than the dam variance at all ages. The shape of the permanent environmental variance was generally similar to dam variance. However, it should be noted that all of those components were small. The most notable trend in management variances was the sharp increase beyond 500 days of age. This indicates the importance of the management group during feedlot period, and in this study, particularly for steers (Figure 1). In contrast, heifers were slaughtered after a short feedlot period ( $\sim 70$ days) at a maximum of 500 days of age.
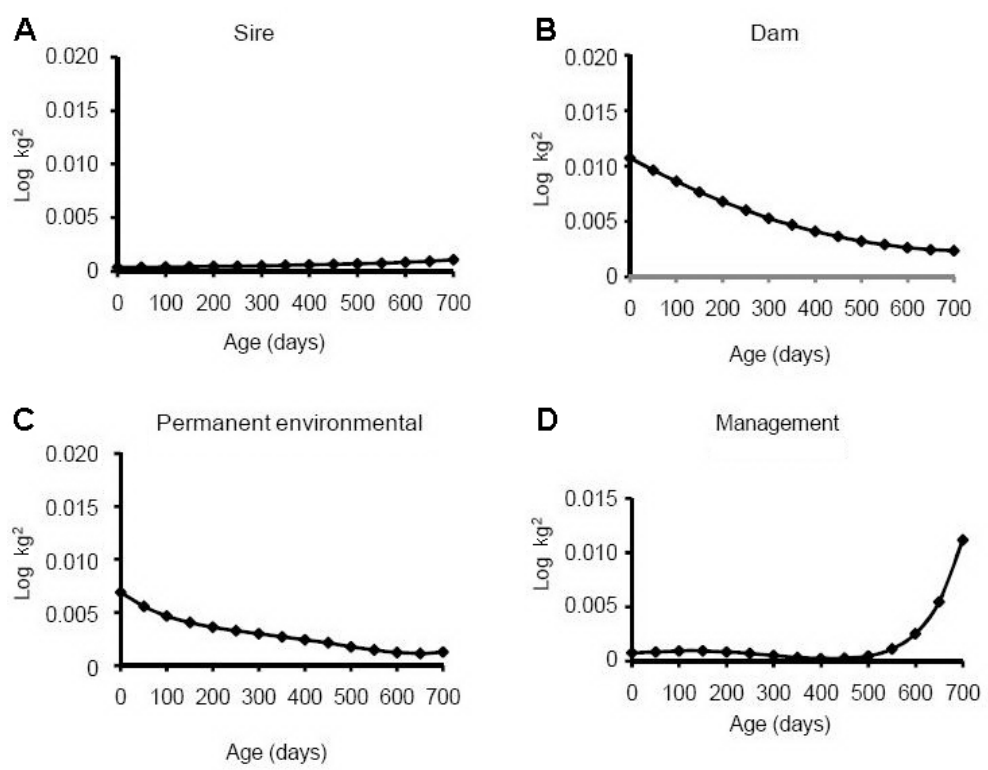

Figure 1. Variance components for sire (A), dam $(\mathbf{B})$, residual $(\mathbf{C})$, and management $(\mathbf{D})$ effects at different ages from birth to slaughter. 
Heritability of live weight increased steadily with age, ranging from 0.08 at birth to 0.92 at 700 days of age (Figure 2). It is possible that since a sire model was fitted, some of the additive genetic variance, especially in young calves, was attributable to the dam component. In general, these results, except for the beginning and the end of the trajectory, were in the range of most values seen in the literature (Mohiuddin, 1993; Koots et al., 1994a; Carnier et al., 2000). This result was consistent with Meyer (1998) who observed that data points at the beginning and end of the lactation trajectory, for which an animal has records, have a relatively large impact on the regression coefficient estimates when polynomials are used as the covariance function. The estimates of additive heritabilities for birth weight were smaller than previously reported in the literature and even for this project when birth weight was treated as a discrete trait (0.31; Pitchford et al., 2006), although that analysis did not include a maternal component and could easily be an overestimate. In contrast, additive heritability beyond 650 days herein was higher than in previous studies (e.g., Koots et al., 1994a).

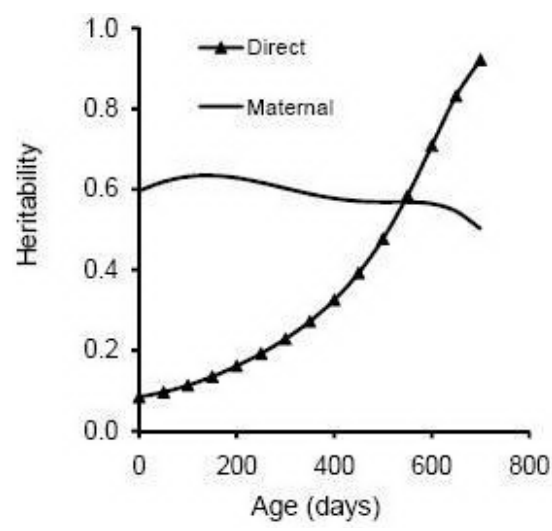

Figure 2. Estimates of additive and dam heritabilities over time.

Dam heritability estimates derived from the cubic sire model were moderate at all ages, ranging from $0.50-0.63$ and fairly constant during the trajectory (Figure 2). Meyer (2002) reported that dam effects decrease with time post-weaning. The magnitude of present estimates was higher than some past estimates reported in the literature. The heritability estimates due to maternal effects on birth weight in order range between 0.03-0.82 in different breeds, 0.1 being the average (Stelzleni et al., 2002). Baker (1980) reported that the average estimates of genetic parameters due to maternal effects on growth traits were higher than those reviewed by Mohiuddin (1993). Contrary to general conclusions in previous studies, maternal heritabilities were higher than additive heritabilities, indicating that growth traits were determined more by the environmental conditions than by those of the genetic characteristics of the calf. However, the patterns of estimates are in agreement with others, where they are highest for birth and weaning weights, followed by yearling, implying importance of maternal effects for birth and weaning weights rather than others. Meyer (1992) concluded that when only one of these effects (maternal genetic or permanent environmental) is considered in the model of analyses, most of the maternal variation is likely to be accounted for. The discrepancy found in various studies could also be attributed to the number and sorts of effects fitted and the mathematical function of the model (Kettunen et al., 1998; Baker et al., 2006). 


\section{Carcass quality (co)variance components}

Almost all carcass variance components ( 36 of 40 ) could be estimated. The environmental or residual variance for HSCW was zero, and hence, there was also no residual covariance between HSCW and the other carcass traits. The relative contribution of variance components to the total phenotypic variance is shown in Figure 3. Management variation was considerable and accounted for 48, 33, 41, and 44\% of total variation for HSCW, P8, EMA, and IMF, respectively. The environmental variance (permanent + temporary) contributions of HSCW, P8, EMA, and IMF were 0 (non-estimable), 56, 29, and 50\%, respectively. The sire variations were $12,6,6$, and $3 \%$ for HCW, P8, EMA, and IMF, respectively. It should be noted that the sire component describes one-quarter of the additive genetic variance. The total genetic (sire + dam) variance was small for fat traits (6-12\%), moderate for EMA (30\%) and large for HSCW (52\%). Heritabilities calculated from the sire variance and excluding management group variance (4.sire / (sire + dam + residual)) were 93, 33, 40, and 20\% for HSCW, P8, EMA, and IMF, respectively.

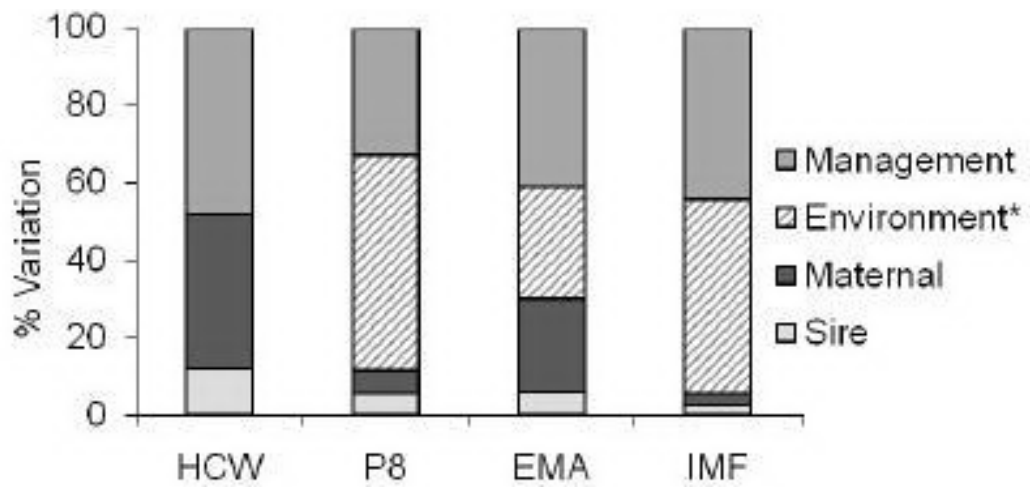

Figure 3. Relative contribution to variation in carcass quality traits. *For carcass traits, environment includes permanent + temporary environmental. For abbreviations, see legend to Table 2 .

The genetic (sire) correlation between HSCW and EMA(0.9; Table 2) was higher than in the analysis of the same data set with an animal model (Pitchford et al., 2006), but most were similar. HCW showed a slightly negative genetic correlation with P8 but was moderately genetically correlated with IMF. Shanks et al. (2001) found similar genetic correlations on an age-constant basis between HSCW and P8 fat depth compared to those herein (0.08; Table 2). However, Koots et al. (1994b) and Marshall (1994) reported that the genetic correlation between HSCW and P8 fat depth is higher and positive. The sire correlations between EMA and fat traits (P8 and IMF) were low and negative. This agrees with several studies conducted at a constant age, whereas other studies have reported stronger negative relationships between EMA and P8 (Koots et al., 1994b; Utrera and Van Vleck, 2004). Studies conducted at a constant weight (Arnold and Bennett, 1991) or constant fat thickness (Gilbert et al., 1993; Johnston et al., 2003) also found larger negative correlations. Brackelsberg et al. (1971) suggested a small negative association between EMA and P8 when evaluated on a constant marbling basis. The negative genetic correlation between EMA and IMF was in agreement with the literature (Koots et al., 1994b; Marshall, 1994), although the genetic correlation was relatively low (-0.14). The sire correlation between P8 and IMF was low. 
As expected, the dam (co)variance component was low for all carcass traits. The dam correlation between HSCW and both EMA and P8 was unity. It was also surprisingly high (0.58) with IMF. The environmental variances were higher than genetic, dam and permanent environmental components (Table 2). Among the carcass traits considered, environmental variances for fat traits were higher than others (Table 2, Figure 3). Management correlations were reasonably high $(>0.76)$ for most traits (except between P8 and IMF). Management correlations between HCW and fat traits ( $\mathrm{P} 8$ and IMF) were higher than the corresponding genetic correlations, and again, HCW was most strongly correlated with EMA. The management correlation between P8 and EMA was high (0.83). The value and direction of the correlation between EMA and IMF for management component were different from those in the genetic correlations. IMF was less correlated with EMA (0.56) and correlated surprisingly little with P8 fat depth (0.26). In general, management correlations were higher than random environmental correlations. Similar patterns as with the genetic correlations were observed for management correlations between fat traits and quantity traits. Residual correlations with HSCW were non-estimable because of the zero variance. Other residual correlations were close to zero with the greatest being between P8 and IMF (0.12).

\section{Growth-carcass (co)variance components}

Since there were 13 (of 16) variances estimated for growth (live-weight cubic not including the covariances) and 15 (of 16) carcass trait variances, there was a potential to estimate 49 rather than 64 covariances between growth and carcass quality. It was possible to estimate 35 of these so that the final model included 95 (co)variance components or the possible 144. A full set of covariances could not be estimated because of factors such as the size of data set, the nature of relationships between traits, lack of variation in pre-weaning growth, limitations of the program used, and the large number of parameters attempted.

There were 8-10 covariances for each of the components (sire, dam, management, and environmental). These values form the basis of the subsequent calculations of correlations. As expected and by definition, there were high associations between growth traits and HSCW. HCW and EMA were most highly correlated with the mean, but P8 and IMF were most highly correlated with the linear growth parameter (Table 2). Mean and linear growth was highly positively correlated with HCW. EMA was not highly genetically correlated with linear growth (0.03), it was highly correlated with mean live weight (0.90; Table 2). It appears that these findings are in line with Moser et al. (1998) who reported genetic correlations between yearling weight and rib-eye area of 0.60 and 0.45 , respectively. Genetic correlations between mean and P8 was low (Table 2); however, the association between linear growth rate and $\mathrm{P} 8$ was positive and moderate. The magnitude of the estimated dam variance mean was approximately twice that of the variance of linear growth. The mean (growth) exhibited strong and linear growth rate, indicating poor dam relationships with $\mathrm{HCW}$. Therefore, no dam influences on growth rate of carcasses were observed. A negative genetic correlation between linear growth rate and P8 existed but was very low. Linear growth and IMF had low dam association. In general, mean and linear growth rate had unfavorable management correlations with carcass traits. The management correlations between mean and carcass quality traits could not be estimated. There was a negative management correlation between P8 and linear growth rate. The management correlation between linear growth rate and IMF was low (Table 2). The permanent environmental correlations between mean, linear and quadratic with 
carcass quality traits appear to be low. However, the permanent environmental correlations between mean, linear and quadratic with HCW could not be estimated (Table 2).

\section{Correlations between growth and carcass traits over time}

The changes in phenotypic correlations between growth and carcass traits over the lifetime of the calves are presented in Figure 4. Phenotypic correlations between growth and fat traits were low at all ages. These correlations have also been partitioned into component sources of variance: sire, dam, management, and permanents environmental correlations (Figure 5). The phenotypic, genetic (sire) and dam correlations of birth weight with HSCW were positive and moderate to high (Figure 5), but the environmental correlations between them were low. The very low environmental correlations between birth weight and HSCW implied that environmental effects on birth weight had little impact on subsequent HSCW, at least for the range of conditions experienced herein. As for birth weight, the environmental correlation between weaning weight and $\mathrm{HSCW}$ was low, indicating independence of the environments that affect both traits. The association between birth weight and EMA was phenotypically low, but genetically very high. Dam and environmental correlations between birth weight and EMA were moderate. Birth weight had low phenotypic, genetic, dam, and management correlations with P8 fat depth. The phenotypic, dam and environmental correlation between birth weight and IMF was positive and low, but the genetic correlation was moderate. The low genetic correlation between the mean and IMF may be due to brown adipose tissue at birth and the fact that fat is mainly deposited in the abdominal cavity and visceral organs at birth, or just that fat levels at birth are very low (Buckley et al., 1990; Smith et al., 2007). The high genetic associations of growth rate and IMF in this study imply that selection for fast growth is likely to change IMF in breeding animals. Veseth et al. (1993) reported that the average genetic correlation between pre-weaning growth and marbling score of Hereford and Simmental cattle was 0.39, indicating a favorable relationship between selection for increased weaning weight and increased marbling. Arnold and Bennett (1991) found that marbling was uncorrelated with weaning weight but marbling was positively correlated with post-weaning gain on a weight-mean basis.

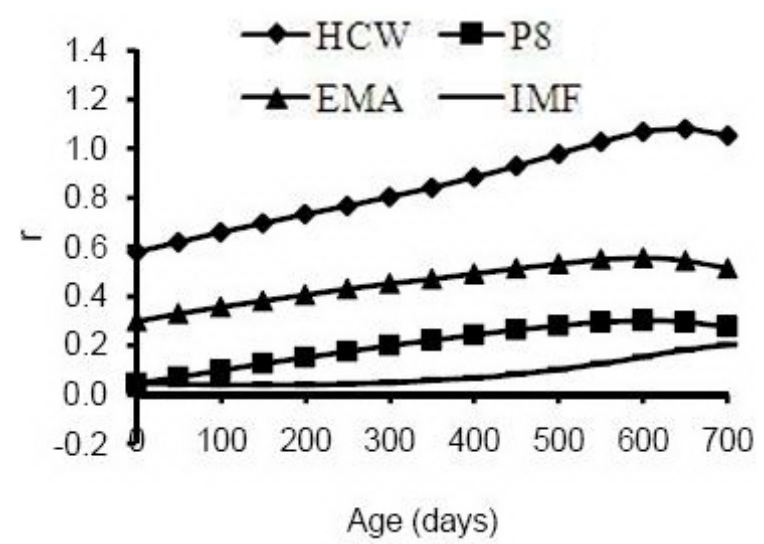

Figure 4. Phenotypic correlations between live weight and carcass traits over time. $\mathrm{HCW}=$ hot carcass weight; P8 = rump fat depth. 

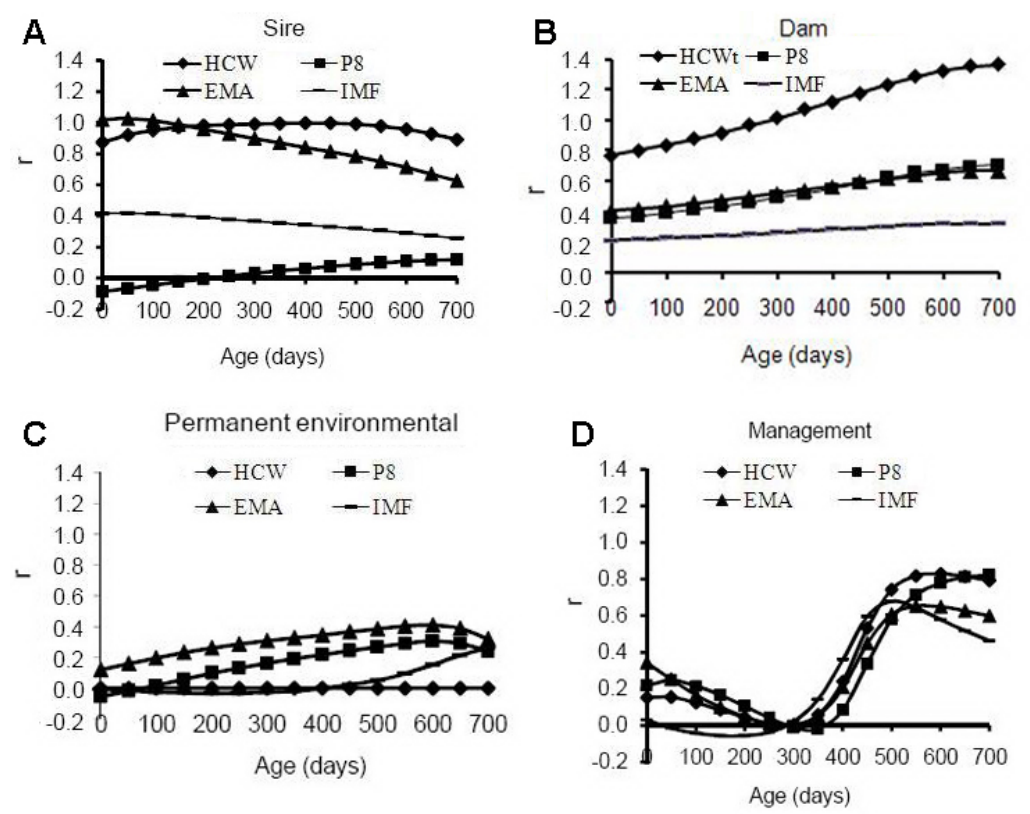

Figure 5. Sire (A), dam (B), residual (C), and management (D) correlations between live weight and carcass traits over time. $\mathrm{HCW}=$ hot carcass weight; P8 = rump fat depth.

Weaning weight and HSCW had favorable phenotypic and genetic correlations. The genetic correlation between weaning weight and EMA was high. The estimates of phenotypic and dam correlations between weaning weight and EMA were moderate, and the environmental correlation between them was low. The estimates of the phenotypic, genetic and environmental correlations between weaning weight and P8 were low and dam correlation between those traits was moderate. The environmental and genetic correlations between the weaning weight and IMF were low to moderate, respectively (Figure 5). High genetic associations of growth rate with $\mathrm{HSCW}$ and P8 fat indicated that high growth will lead to heavier carcasses with greater fat depth. Previous reports confirm the positive genetic correlations between fat thickness and pre-weaning growth (Koch et al., 1994) and post-weaning growth (Arnold and Bennett, 1991). This may be expected because as the cattle progress from birth to mature weight, there is a large increase in the percentage of fat. Koots et al. (1994b) reported genetic correlations of $0.24,0.32$ and 0.19 between fat depth and weaning, yearling weights and postweaning gain, respectively. The pre-weaning body weights were negatively related genetically to P8 fat depth (Figure 5), in general agreement with Arnold and Bennett (1991) and Crews Jr. and Kemp (1999). The negative relationship between weaning weight and P8 fat depth could be related to maturing rate. Animals that are heavier at weaning may mature slowly and consequently could have increased amounts of lean muscle tissue relative to external fat. Koots et al. (1994a), Marshall (1994), Hennessy and Morris (2003), and Hennessy and Arthur (2004) reported that those animals that had higher pre-weaning growth had heavier carcasses although they also tended to be fatter than carcasses from animals that had low pre-weaning growth rates. However, it is equally possible that the negative correlations are simply low correlations 
that have become negative because of the inflexibility of the cubic polynomial. This could be an argument for using a cubic spline, although partitioning the spline into the components herein (sire, dam, management, residual) is non-trivial. The management correlations (Figure 5 ) indicate that there was negligible relationship between growth of calves during their first year and subsequent carcass quality. This is supported by the study of Greenwood et al. (2006) and early study by Tudor et al. (1980) where growth path was substantially altered as part of the experimental design. Both studies concluded that while slowing a calf's growth meant that target carcass weights took longer to attain, there were no adverse effects on beef quality and only small effects on carcass composition.

Phenotypic, genetic and dam correlations were found to be positive and high for postweaning body weights with HSCW (Figure 5). The management correlations between yearling body weight and HSCW were low, but as age increased they sharply increased during the post-weaning period. There was a moderate to high, positive genetic correlation between post-weaning growth and EMA. The phenotypic correlation between yearling weight and fat traits (P8 and IMF) was low. There was a low phenotypic and management relationship and a moderate genetic and dam relationship between yearling weight and IMF. Residual correlations were low with all carcass traits.

\section{CONCLUSION}

To meet demands for quality beef, beef producers need to consider not only growth but also carcass traits in selection decisions. Knowledge of growth-carcass curve shape, in particular its non-genetic determination, would be of interest for optimizing breeding goals and management practices to meet market specifications. From a selection standpoint, early growth was genetically correlated with HSCW and EMA but not with carcass fatness. Management of cattle in their first year was not a major determinant of carcass quality, suggesting that as long as calves are healthy, growth rate is of little importance. However, not surprisingly, management (growth rate) during the feedlot phase was crucial for all four carcass traits. Cattle growth traits are determined more by the environmental conditions than by the genetic characteristics. In both growth and carcass traits, the management effects were larger than genetic, dam or permanent environmental. For obtaining "better" estimates of (co)variance components, the use of a larger data set as well as mathematical functions other than polynomials would be helpful. High growth will lead to heavier carcasses with more fat depth and will likely change IMF in breeding animals. Increasing HCW would increase the genetic potential for EMA but may reduce marbling and tend to slightly increase P8.

\section{REFERENCES}

Aitchison J and Brown JAC (1963). The Lognormal Distribution. Cambridge University Press, Cambridge.

Arnold RN and Bennett GL (1991). Evaluation of four simulation models of cattle growth and body composition: Part I - comparison and characterization of the models. Agric. Syst. 35: 401-432.

AUSMEAT (1995). The Users' Guide to Australian Meat. 1st edn. Meat and Livestock, Australia.

Baker MJ, Tedeschi LO, Fox DG, Henning WR, et al. (2006). Using ultrasound measurements to predict body composition of yearling bulls. J. Anim. Sci. 84: 2666-2672.

Baker RL (1980). The role of maternal effects on the efficiency of selection in beef cattle - a review. New Zeal. Soc. Anim. Prod. 40: 285-303.

Bergen R, Miller SP, Wilton JW, Crews DH Jr, et al. (2006a). Genetic correlations between live yearling bull and steer 
carcass traits adjusted to different slaughter end points. 1. Carcass lean percentage. J. Anim. Sci. 84: 546-557.

Bergen R, Miller SP, Wilton JW and Mandell IB (2006b). Genetic correlations between live yearling bull and steer carcass traits adjusted to different slaughter end points. 2. Carcass fat partitioning. J. Anim. Sci. 84: 558-566.

Brackelsberg PO, Kline EA, Willham RL and Hazel LN (1971). Genetic parameters for selected beef-carcass traits. $J$. Anim. Sci. 33: 13-17.

Buckley BA, Baker JF, Dickerson GE and Jenkins TG (1990). Body composition and tissue distribution from birth to 14 months for three biological types of beef heifers. J. Anim. Sci. 68: 3109-3123.

Carnier P, Albera A, Dal Zotto R, Groen AF, et al. (2000). Genetic parameters for direct and maternal calving ability over parities in Piedmontese cattle. J. Anim. Sci. 78: 2532-2539.

Crews DH Jr and Kemp RA (1999). Contributions of preweaning growth information and maternal effects for prediction of carcass trait breeding values among crossbred beef cattle. Can. J. Anim. Sci. 79: 17-25.

Crews DH Jr, Pollak EJ, Weaber RL, Quaas RL, et al. (2003). Genetic parameters for carcass traits and their live animal indicators in Simmental cattle. J. Anim. Sci. 81: 1427-1433.

Fischer TM, van der Werf JHJ, Banks RG and Ball AJ (2004). Description of lamb growth using random regression on field data. Livest. Prod. Sci. 89: 175-185.

Gilbert RP, Bailey DR and Shannon NH (1993). Body dimensions and carcass measurements of cattle selected for postweaning gain fed two different diets. J. Anim. Sci. 71: 1688-1698.

Gilmour AR, Bulls BR, Welham SJ and Thompson R (2000). ASREML - Reference Manual. NSW Agriculture Biometric Bulletin No. 3. NSW Agriculture, Orange Agricultural Institute, Orange.

Greenwood PL, Cafe LM, Hearnshaw H, Hennessy DW, et al. (2006). Long-term consequences of birth weight and growth to weaning on carcass, yield and beef quality characteristics of Piedmontese- and Wagyu-sired cattle. Aust. J. Exp. Agr. 46: 257-269.

Hennessy DW and Morris SG (2003). Effect of a preweaning growth restriction on the subsequent growth and meat quality of yearling steers and heifers. Aust. J. Exp. Agr. 43: 335-341.

Hennessy DW and Arthur PF (2004). The effect of preweaning growth restriction on the feed intake and efficiency of cattle on a grain-based diet before slaughter. Aust. J. Exp. Agr. 44: 483-488.

Johnston DJ, Reverter A, Ferguson DM, Thompson JM, et al. (2003). Genetic and phenotypic characterisation of animal, carcass, and meat quality traits from temperate and tropically adapted beef breeds. 3. Meat quality traits. Aust. J. Agr. Res. 54: 135-147.

Kahi AK, Oguni T, Sumio Y and Hirooka H (2007). Genetic relationships between growth and carcass traits and profitability in Japanese Brown cattle. J. Anim. Sci. 85: 348-355.

Kettunen A, Mantysaari EA, Strandén I, Poso J, et al. (1998). Estimation of Genetic Parameters for First Lactation Test Day Milk Production Using Random Regression Models. In: Proceedings of the 6th World Congress on Genetics Applied to Livestock Production, Armidale.

Kilpatrick DJ and Steen RWJ (1999). A predictive model for beef cattle growth and carcass composition. Ag. Syst. 61: 95-107.

Koch RM, Cundiff LV and Gregory KE (1994). Cumulative selection and genetic change for weaning or yearling weight or for yearling weight plus muscle score in Hereford cattle. J. Anim. Sci. 72: 864-885.

Koots KR, Gibson JP, Smith C and Wilton JW (1994a). Analyses of published genetic parameter estimates for beef production traits. 1. Heritability. Anim. Breed. Abstr. 62: 309-338.

Koots KR, Gibson JP and Wilton JW (1994b). Analyses of published genetic parameter estimates for beef production traits. 2. Phenotypic and genetic correlations. Anim. Breed. Abstr. 62: 825-853.

Lambe NR, Navajas EA, McLean KA, Simm G, et al. (2007). Changes in carcass traits during growth in lambs of two contrasting breeds, measured using computer tomography. Livest. Sci. 107: 37-52.

Limpert E, Stahel WA and Abbt M (2001). Log-normal distributions across the sciences: keys and clues. Bioscience 51: 341-352.

Marshall DM (1994). Breed differences and genetic parameters for body composition traits in beef cattle. J. Anim. Sci. 72: 2745-2755.

Meyer K (1992). Variance components due to direct and maternal effects for growth traits of Australian beef cattle. Livest. Prod. Sci. 31: 179-204.

Meyer K (1998). Estimating covariance functions for longitudinal data using a random regression model. Genet. Sel. Evol. 30: $221-240$.

Meyer K (2002). Estimates of covariance functions for growth of Australian beef cattle from a large set of field data. In: Proceedings of the Seventh World Congress of Genetics Applied to Livestock Production. CD-ROM Communication. Vol. 11-01. Montpellier.

Mohiuddin G (1993). Estimates of genetic and phenotypic parameters of some performance traits in beef cattle. Anim. Breed. Abst. 61: 495-522. 
Moser DW, Bertrand JK, Misztal I, Kriese LA, et al. (1998). Genetic parameter estimates for carcass and yearling ultrasound measurements in Brangus cattle. J. Anim. Sci. 76: 2542-2548.

Pitchford WS, Deland MP, Siebert BD, Malau-Aduli AE, et al. (2002). Genetic variation in fatness and fatty acid composition of crossbred cattle. J. Anim. Sci. 80: 2825-2832.

Pitchford WS, Mirzaei HR, Deland MPB, Afolayan RA, et al. (2006). Variance components for birth and carcass traits of crossbred cattle. Aust. J. Exp. Agr. 46: 225-231.

Rekaya R, Carabaño MJ and Toro MA (1999). Use of test day yields for the genetic evaluation of production traits in Holstein-Friesian cattle. Livest. Prod. Sci. 57: 203-217.

Schenkel FS, Miller SP and Wilton JW (2004). Genetic parameters and breed differences for feed efficiency, growth, and body composition traits of young beef bulls. Can. J. Anim. Sci. 84: 177-185.

Shanks BC, Tess MW, Kress DD and Cunningham BE (2001). Genetic evaluation of carcass traits in Simmental-sired cattle at different slaughter end points. J. Anim. Sci. 79: 595-604.

Smith T, Domingue JD, Paschal JC, Franke DE, et al. (2007). Genetic parameters for growth and carcass traits of Brahman steers. J. Anim. Sci. 85: 1377-1384.

Stelzleni AM, Perkins TL, Brown AH Jr, Pohlman FW, et al. (2002). Genetic parameter estimates of yearling live animal ultrasonic measurements in Brangus cattle. J. Anim. Sci. 80: 3150-3153.

Tudor GD, Utting DW and O'Rourke PK (1980). The effect of pre- and post-natal nutrition on the growth of beef cattle. 3. The effect of severe restriction in early post-natal life on the development of the body components and chemical composition. Aust. J. Agr. Res. 31: 191-204.

Utrera AR and Van Vleck LD (2004). Heritability estimates for carcass traits of cattle: a review. Genet. Mol. Res. 3: 380-394.

Veseth DA, Reynolds WL, Urick JJ, Nelsen TC, et al. (1993). Paternal half-sib heritabilities and genetic, environmental, and phenotypic correlation estimates from randomly selected Hereford cattle. J. Anim. Sci. 71: 1730-1736. 